\title{
Regulation of cobalamin-like synthase gene expression through a zinc-responsive transcriptional element
}

\author{
J. Tyson, E. A. E. van der Hagen, L. J. Coneyworth, L. S. Bell, J. N. Hadfield and D. Ford \\ Institute for Cell and Molecular Biosciences, Newcastle University, Newcastle upon Tyne NE2 4HH, UK
}

\begin{abstract}
Maintenance of $\mathrm{Zn}$ homeostasis is essential for health and cellular function; however, the transcriptional control of $\mathrm{Zn}$ responsive genes is currently poorly characterised. A novel Zinc Responsive Transcriptional element (ZRE) within the promoter region of the SLC30A5 Zn transporter gene was identified and an in silico search for the ZRE identified 6 human paralogous COBW domain-containing ( $C B D W$ ) genes as potentially responsive to $\mathrm{Zn}$. Furthermore, comparative genomic analysis of prokaryotic $C B W D$ homologues has revealed a potential role in metal homeostasis and trafficking ${ }^{(1)}$.

The abundance of the $C B W D$ transcript in Caco-2 cells, normalised to GAPDH, was measured by RT-qPCR to be $\sim 50 \%$ lower $(P<0.001)$ in cells treated for $24 \mathrm{~h}$ with $100 \mu \mathrm{M} \mathrm{Zn}(0.48 \pm 0.06, n 6)$ compared with $3 \mu \mathrm{M} \mathrm{Zn}(1.00 \pm 0.09, n 6)$. Zn-regulated $C B D W$ transcription and the role of the ZRE was investigated using plasmid constructs comprising the region -1078 to +98 of the $C B D W 3$ gene, relative to the start of transcription, upstream of the $\beta$-galactosidase reporter gene in the vector pBlueTOPO (Invitrogen). Reporter gene expression was lower $(P<0.001)$ at $100 \mu \mathrm{M} \mathrm{Zn}(0.73 \pm 0.04, n 23)$ compared with $3 \mu \mathrm{M} \mathrm{Zn}(1.00 \pm 0.04 ; n 24)$ in transfected Caco-2 cells treated with $\mathrm{Zn}$ for $24 \mathrm{~h}$. The response of the reporter gene to $\mathrm{Zn}$ was attenuated $(P<0.01)$ by mutating the $\mathrm{ZRE}$ to a random sequence $(1.00 \pm 0.03$ at $3 \mu \mathrm{M} \mathrm{Zn;} 0.90 \pm 0.02$ at $100 \mu \mathrm{M}$ zinc; $n$ 12), consistent with the ZRE having a role in mediating the transcriptional response to $\mathrm{Zn}$.

Human CBWD3 protein, incorporating a C-terminal FLAG tag, was expressed transiently from a plasmid construct comprising the full open reading frame of the human $C B D W 3$ gene in the vector pCMV6Entry (Origene) in chinese hamster ovary cells treated for $24 \mathrm{~h}$ with 3 or $100 \mu \mathrm{M} \mathrm{Zn}$. Western-blot analysis using an anti-FLAG antibody indicated greater abundance $(P<0.05)$ of the recombinant protein resolved by SDS-PAGE at the expected molecular weight $(\sim 44 \mathrm{kDa})$ in cells cultured at the higher $\mathrm{Zn}$ concentration $(1.00 \pm 0.12$ at $3 \mu \mathrm{m}$ $\mathrm{Zn} ; 2.57 \pm 0.36$ at $100 \mu \mathrm{M} \mathrm{Zn}$; derived by densitometric quantification of band intensity, $n$ 3-4). Preliminary observations indicated increased abundance at the lower $\mathrm{Zn}$ concentration of an anti-FLAG immunoreactive band of a lower molecular weight $(\sim 30 \mathrm{kDa})$, possibly indicative of $\mathrm{Zn}$-dependent cleavage.

These observed effects of $\mathrm{Zn}$ availability on the expression of the $C B D W$ genes and CBDW protein are consistent with the view that the human CBDW proteins play a role in Zn homeostasis. Further studies, including the identification of CBDW protein-binding partners, description of tissue and sub-cellular distribution and effects of $\mathrm{Zn}$ and other divalent metals on these measures, may help to elucidate this role.
\end{abstract}

Funded by BBSRC grant ref. BB/F019637/1.

1. Haas CE, Rodinov DA, Kropat J et al. (2009) A subset of the diverse COG0526 family of putative metal chaperones is linked to zinc homeostasis in all kingdoms of life. BMG Genomics 10, 470. 